\title{
Intracoronary Autologous CD34+ Stem Cell Therapy for Intractable Angina
}

\author{
Shihong Wang Junyu Cui Wei Peng Min Lu \\ Department of Cardiovascular Medicine, General Hospital of Beijing Military Region of PLA, Beijing, China
}

\section{Key Words}

Myocardial ischemia $\cdot$ Bone marrow $\cdot$ Stem cells •

Intracoronary infusion $\cdot$ Angiogenesis

\begin{abstract}
Background/Objectives: A large number of patients with coronary artery disease experience angina that is not suitable for revascularization and is refractory to conventional medical therapy. Laboratory and preclinical studies have provided evidence for the safety and potential efficacy of autologous CD34+ stem cell therapies as treatment for angina. Clinical studies investigating intramyocardial transplantation of autologous CD34+ stem cells by catheter injection for patients with refractory angina show that this is safe and feasible. It remains unclear whether intracoronary infusion of CD34+ stem cells exerts beneficial effects in patients with angina as well. We addressed this question with a controlled clinical trial by enrolling 112 patients with refractory angina. Previous trials have investigated the safety and beneficial effects of CD34+ cells isolated from granulocyte colony-stimulating factor-mobilized peripheral blood; in our trial, we isolated CD34+ cells directly from the patient's bone marrow. Methods: One hundred and twelve patients with diffuse triple-vessel disease and Canadian Cardiovascular Society class III or IV angina were enrolled in a double-blind, randomized (1:1), placebo-controlled study. Patients received optimal medical treatment but were not candidates
\end{abstract}

for mechanical revascularization (percutaneous coronary intervention or coronary artery bypass grafting). Fifty-six patients ( 27 women and 29 men aged $42-80$ years) were enrolled in the treatment group, and 56 patients ( 28 women and 28 men aged $43-80$ years) who received optimal medical treatment and intracoronary saline injections were enrolled in the placebo control group. Bone marrow was collected from all enrolled patients at a volume of $120-150 \mathrm{ml}$ each in both groups. Selections of CD34+ cells were performed by a CE-marked device approved by the Security, Food and Drug Administration of China. Coronary angiography had been performed before enrollment in this study. Results: No myocardial infarction was observed during intracoronary infusion. The intracoronary infusion of cells or saline did not result in cardiac enzyme elevation, cardiac perforation or pericardial effusion. No arrhythmia, such as ventricular tachycardia or ventricular fibrillation, was induced by intracoronary infusion. No serious adverse events occurred in either group. The reduction in the frequency of angina episodes per week 3 and 6 months after infusion was significantly higher in the treatment group $(-14.6 \pm 4.8$ at 3 months and $-15.6 \pm 4.0$ at 6 months) than in the control group $(-4.5 \pm 0.3$ and $-3.0 \pm 1.2$, respectively; $p<0.01)$. Other efficacy parameters such as nitroglycerine usage, exercise time and the Canadian Cardiovascular Society class also showed an improvement in the treatment group compared to the control group. A significant improvement in myocardial perfusion was noted in the treatment group

\section{KARGER}

Fax +41613061234 E-Mail karger@karger.ch www.karger.com
(C) 2010 S. Karger AG, Basel

0008-6312/10/1172-0140\$26.00/0

Accessible online at:

www.karger.com/crd
Shihong Wang, MD

Department of Cardiovascular Medicine

General Hospital of Beijing Military Region of PLA

Nan Men Cang 5, Dongcheng District, Beijing 100700 (China)

Tel. +8610 6672 6929-8034, Fax +86 106672 1161, E-Mail Shihongw1@yahoo.com.cn 
compared to the control group, as measured by single-photon emission computed tomography. Conclusions: This randomized trial investigating intracoronary infusion of autologous CD34+ cells in patients with intractable angina shows the safety and feasibility of this therapy and provides evidence for efficacy.

Copyright $\odot 2010$ S. Karger AG, Base

\section{Introduction}

Despite improvement in perfusion by conventional antianginal medications and interventional revascularization, many patients with coronary artery disease continue to have severe angina $[1,2]$. It is estimated that 20 $30 \%$ of patients with diffuse triple-vessel disease in China who have failed to respond to conventional medical therapies continue to experience angina. About 1,000-2,000 new patients are hospitalized per year in the General Hospital of Beijing Military Region of PLA. Thus, there is a strong medical need for the development of new therapies for this patient population.

A study by Losordo et al. [3] showed the efficacy of intramyocardial transplantation of autologous granulocyte colony-stimulating factor-mobilized peripheral blood CD34+ stem cells for the treatment of angina. However, it had a potential to increase the risk of myocardial infarction and inconvenient NOGA-guided operations [3-5]. Laboratory and preclinical studies have provided evidence for the safety and potential efficacy of intracoronary autologous CD34+ stem cell infusion for cell regeneration following myocardial infarction [6, 7]. Accordingly, we initiated a pilot, first-in-human study to evaluate the safety, feasibility and bioactivity of intracoronary transplantation of bone marrow CD34+ stem cells for intractable angina.

\section{Patients and Methods}

\section{Study Design}

This was a randomized, placebo-controlled clinical trial (registered to the Health Department of PLA, People's Republic of China). One hundred and twelve patients were enrolled in the study and divided between the CD34+ cell treatment and placebo control groups. The patients and researchers were unaware of the treatments. All patients underwent bone marrow collection. The CD34+ cell fraction was purified using a commercially available device (CliniMACS ${ }^{\circledR}$ System, Miltenyi Biotec, Bergisch Gladbach, Germany) according to the manufacturer's instructions. Cells were then subjected to testing and were required to meet lot release criteria, which included sterility, viability and the absence of en- dotoxin content. Once cells passed the lot release criteria, the patients underwent coronary angiography and received an intracoronary infusion of CD34+ cells [suspended in saline plus human serum albumin (HSA)] or cell diluents (saline plus HSA) using an over-the-wire balloon guiding catheter (Cordis) [8]. Ten and $5 \mathrm{ml}$ of cell suspension or placebo solution were infused separately into the right coronary artery and the left main coronary artery. Patients were discharged from hospital several days after the infusion procedure. Follow-up took place 1,2 and 4 weeks and 3 and 6 months after the procedure. Single-photon emission computed tomography (SPECT) was performed at baseline and 6 months after the procedure by a single technician who was unaware of the trial.

Selection of Patients

Enrollment criteria included age over 30 years, diffuse triplevessel disease and functional Canadian Cardiovascular Society (CCS) class III or IV angina. Patients were receiving conventional medical therapy, including long-acting nitrates, maximal use of $\beta$-adrenergic blocking agents and calcium channel agents, without control of their angina. Patients were required to be considered noncandidates for conventional revascularization by a cardiologist. A cardiac surgeon had to have reviewed the most recent (within 6 months) angiogram to verify ineligibility for surgical revascularization. Patients were also required to have ischemia on nuclear perfusion imaging, to complete at least $1 \mathrm{~min}$ but no more than 6 min of a standard Bruce protocol and to experience angina during the baseline exercise test. Patients were unaware of which treatment they received.

Key exclusion criteria included myocardial infarction within 30 days of treatment; successful coronary revascularization within 3 months of enrollment; documented transient ischemic attack within 60 days of treatment; severe aortic stenosis or insufficiency; severe mitral stenosis or severe mitral insufficiency; predominant congestive heart failure symptoms; severe comorbidities associated with a reduction in life expectancy to less than 1 year; uncontrolled hypertension, and joint disease, peripheral vascular disease or chronic obstructive pulmonary disease that would limit walking on a treadmill.

\section{Bone Marrow Collection and Stem Cell Selection}

Bone marrow $(120-150 \mathrm{ml})$ was aspirated from the posterior iliac crest under local anesthesia by a doctor who was unaware of the treatment. Bone marrow cells were then magnetically labeled with CliniMACS CD34 Reagent and separated using the CliniMACS System (Miltenyi Biotec) in a procedure derived from the manufacturer's instructions. After elution from the instrument, CD34+ cells were spun down and resuspended in 15 $\mathrm{ml}$ of saline plus HSA by a technician who was unaware of the treatment.

\section{Bone Marrow Stem Cell Infusion}

The equipment we used for infusing intracoronary stem cells and placebo was the GE Innova 2000 DSA. The amount of heparin used was 3,000 IU. Approximately 1-2 h after the completion of the CD34+ cell separation, $10 \mathrm{ml}$ of cells and $5 \mathrm{ml}$ of saline were infused into the proximal left main coronary artery and right coronary artery separately by an over-the-wire balloon. The balloon was inflated to a 1:1 diameter ratio, the guide wire was removed and $2 \mathrm{ml}$ of the specimen was infused at $1 \mathrm{ml} / \mathrm{min}$. The balloon was then deflated and the vessel reperfused for $2 \mathrm{~min}$. The balloon 
was then reinflated and the process repeated until the entire $15-$ $\mathrm{ml}$ dose was delivered. The mean number of CD34+ cells infused was $5.6 \pm 2.3 \times 10^{7}$ (all cells sorted from the bone marrow specimen and checked by flow cytometry). The percent viability of the stem cells was $94-96 \%$.

\section{End Points}

Safety

An independent data safety monitoring board reviewed safety data in a timely manner. In addition to routine physical examination and laboratory testing, patients were also monitored with ECG, transthoracic echocardiography and thoracic X-ray at regular intervals. Echocardiography was performed immediately after the infusion procedure and before hospital discharge in all subjects.

\section{Arrhythmia Monitoring}

A 24-hour Holter monitoring was required by all patients before infusion and 1 week and 3, 6 and 12 months after infusion.

\section{Efficacy}

Bioactivity was assessed according to the parameters discussed in the following sections.

\section{Angina Frequency}

The frequency of angina per week in both the groups was assessed by a colleague (Xuan Zhang) who was unaware of the treatment in detail. Patient outcomes were confirmed by patient reports during the study period both inside and outside the hospital.

\section{Nitroglycerine Use}

Nitroglycerine (NTG) use per week in both the groups was assessed by Xuan Zhang. Researchers were unaware of the treatment in detail, and drug distribution was confirmed by patient reports during the study period both inside and outside the hospital.

\section{Exercise Tolerance}

Symptom-limited treadmill exercise tolerance tests (ETTs), using the standard Bruce protocol (Case 8000, Marquette Electronics Inc., Fla., USA), were performed in the morning and at approximately the same time of day at each visit. Time to onset of angina and time to limiting angina during the ETT were determined by the investigator, whereas total exercise duration and time to 1-mm ST segment depressions were determined by central reading. Heart rate was obtained from the ECG recording and a rate-pressure product (heart rate - systolic blood pressure).

During the run-in period, ETTs were considered positive if they were stopped secondary to the occurrence of limiting angina pectoris and accompanied by at least $1 \mathrm{~mm}$ of ST segment depression with 1-6 min of exercise. During the study period (i.e. at months 2 and 4), ETT could continue beyond 6 min or stop before $1 \mathrm{~min}$. Stopping criteria included limiting angina pectoris, dyspnea and extreme fatigue. The ST segment was measured $80 \mathrm{~ms}$ after the J point in 3 consecutive QRS complexes with a flat baseline. If ST segment depression was present at rest, the change was calculated from the value at rest to the value during exercise. If ST segment elevation was present at rest, ST depression during exercise was calculated from the ECG isoelectric line. Thus, the time to $1-\mathrm{mm}$ ST segment depression was calculated as the time to 1-mm ST segment depression in the case of an isoelectric or elevated ST segment at rest and as the time to a depression of greater than $1 \mathrm{~mm}$ in the case of ST depression at rest. During this study, if neither a 1-mm ST segment depression nor angina occurred during the ETT, the total exercise duration was used as the measure of time to 1-mm ST segment depression and time to onset of angina.

ETT and ECG tracings were analyzed centrally at a reading center by cardiologists blinded to treatment allocation. When reading the 2 - and 4-month ETT tracings during the study period, the cardiologist did not have access to previous ETT data.

\section{CCS Class}

The CCS class was defined according to the CCS Functional Classification as follows. Class I: ordinary physical activity, such as walking and climbing stairs, which does not cause angina. Angina with strenuous, rapid or prolonged exertion at work or recreation. Class II: slight limitation of ordinary activity. Walking or climbing stairs rapidly, walking uphill, walking or stair climbing after meals, in cold, in wind, under emotional stress or only during the few hours after waking up. Walking more than two blocks on the level and climbing more than one flight of ordinary stairs at a normal pace and in normal conditions. Class III: marked limitation of ordinary physical activity. Walking one to two level blocks and climbing more than one flight of stairs in normal conditions. Class IV: inability to carry out any physical activity without discomfort; anginal syndromes may be present at rest. The CCS class was assessed by a single technician who was unaware of the treatment.

\section{SPECT Perfusion Imaging}

For 201-thallium SPECT, patients performed a symptom-limited bicycle ergometer exercise test with continuous monitoring and a 12-lead ECG recording for each minute of exercise. At nearmaximal exercise, 201-thallium was injected intravenously and exercise was continued for $1 \mathrm{~min}$ after injection. Patients were imaged in the supine position beginning $10 \mathrm{~min}$ after exercise. Resting images were acquired 3-4 h later. Semiquantitative visual interpretation of SPECT perfusion images used short-axis and vertical long-axis tomograms. Each patient was assessed by a consensus of two expert observers (who were unaware of the treatment) using percent perfusion of the defective area. The sum of the differences between the stress and resting values of each patient was calculated.

\section{Statistical Analysis}

Since this was a first-in-human study, no prior data were available on which to base power calculations. Accordingly, results are presented as changes from baseline to follow-up in patients assigned to placebo versus those assigned to cell infusion. A statistical assessment of efficacy was performed, and certain parameters revealed significant improvement. Because the crossover of placebo-assigned patients was permitted after 6 months, the analysis of efficacy parameters is restricted to 6 months after the initial treatment assignment. All values are expressed as means $\pm \mathrm{SE}$. Paired Student's t tests were performed for comparison of the data before and after treatment. Comparisons between the 2 groups were made using one-way analysis of variance. A probability value $<0.05$ was considered to denote statistical significance. 
In compliance with the 'Administrative Regulations on Medical Institutions' (State Council of the People's Republic of China, 1994.09.01), all patients gave their informed consent and the study protocol was approved by the ethical committee on human research of the General Hospital of Beijing Military Region of PLA. The authors had full access to the data and take full responsibility for its integrity.

\section{Results}

\section{Patients}

The baseline characteristics of the patients are shown in table 1. Fifty-six patients (27 women and 29 men aged 42-80 years) were enrolled in the treatment group, and 56 patients ( 28 women and 28 men aged $43-80$ years) who received optimal medical treatment and intracoronary saline injection were enrolled in the placebo control group. They were enrolled at a single center in China from January 2007 through December 2008. There were no significant differences between the 2 groups with regard to baseline characteristics.

\section{Safety Analysis}

No increase in angina frequency or usage of sublingual NTG was observed in the patients of either group. There were no cardiac enzyme elevations, myocardial infarctions, acute coronary syndromes or deaths. Serious adverse events (table 2) were distributed evenly between the 2 groups. No patients from either group developed ventricular tachycardia during the cell or saline infusion procedure. No arrhythmias were detected by Holter monitoring in any patient during or after the infusion process.

\section{Efficacy Analysis}

Angina Frequency

At baseline, patients in the control group experienced $20.5 \pm 3.5$ episodes of angina per week compared to 21.2 \pm 6.1 episodes of angina per week in the treatment group. Three months after infusion, the frequency of angina had decreased in both the placebo and treatment groups (16.0 \pm 3.2 episodes in the control group vs. $6.6 \pm 1.3$ in the treated group). Six months after infusion, the frequency of angina was further reduced in both the control group and CD34+ cell-treated patients $(15.5 \pm 3.3$ vs. $5.6 \pm 2.1$ episodes). At both time points, the CD34+ stem celltreated patients experienced a greater reduction of symptoms (change from baseline: controls, $-4.5 \pm 0.3$ episodes at 3 months and $-3.0 \pm 1.2$ at 6 months; CD34+ cell treatment, $-14.6 \pm 4.8$ episodes at 3 months and $-15.6 \pm$ 4.0 episodes at 6 months; table 3 ).
Table 1. Baseline characteristics according to treatment group

\begin{tabular}{lccc}
\hline & $\begin{array}{c}\text { Placebo } \\
(\mathrm{n}=56)\end{array}$ & $\begin{array}{l}\text { CD34+ cells } \\
(\mathrm{n}=56)\end{array}$ & $\mathrm{p}$ \\
\hline Hyperlipidemia & $32(57)$ & $31(55)$ & $>0.05$ \\
Hypertension & $24(43)$ & $22(39)$ & $>0.05$ \\
Smoking history & $12(21)$ & $11(20)$ & $>0.05$ \\
Congestive heart failure & $3(5)$ & $4(7)$ & $>0.05$ \\
Myocardial infarction & $6(11)$ & $5(9)$ & $>0.05$ \\
Peripheral vascular disease & $10(18)$ & $11(20)$ & $>0.05$ \\
Diabetes mellitus & $23(50)$ & $25(45)$ & $>0.05$ \\
ACE inhibitors & $41(71)$ & $40(71)$ & $>0.05$ \\
3-Blockers & $36(64)$ & $36(64)$ & $>0.05$ \\
Calcium channel agents & $37(66)$ & $38(68)$ & $>0.05$ \\
Long-acting nitrates & $40(71)$ & $39(70)$ & $>0.05$ \\
Statins & $30(54)$ & $29(52)$ & $>0.05$ \\
Prior PCI procedure(s) & $2(4)$ & $3(5)$ & $>0.05$ \\
Prior CABG surgery & $1(2)$ & $2(3)$ & $>0.05$ \\
\hline
\end{tabular}

Values are expressed as numbers of patients (percentages in parentheses). $\mathrm{ACE}=$ Angiotensin-converting enzyme; $\mathrm{PCI}=$ percutaneous coronary intervention; $\mathrm{CABG}=$ coronary artery bypass grafting.

Table 2. Incidence of serious adverse events

\begin{tabular}{llll}
\hline & $\begin{array}{l}\text { Placebo } \\
(\mathrm{n}=56)\end{array}$ & $\begin{array}{l}\text { CD34+ cells } \\
(\mathrm{n}=56)\end{array}$ & $\mathrm{p}$ \\
\hline Atrial arrhythmia & $2(3)$ & $1(2)$ & $>0.05$ \\
Ventricular arrhythmia & $1(2)$ & $0(2)$ & $>0.05$ \\
Angina exacerbation & $3(5)$ & $2(3)$ & $>0.05$ \\
Congestive heart failure & $0(0)$ & $0(0)$ & $>0.05$ \\
Respiratory arrest & $0(0)$ & $0(0)$ & $>0.05$ \\
Cerebrovascular accident & $0(0)$ & $1(2)$ & $>0.05$ \\
Peripheral vascular claudication & $0(0)$ & $0(0)$ & $>0.05$ \\
Bleeding/anemia & $0(0)$ & $0(0)$ & $>0.05$ \\
Renal insufficiency & $2(3)$ & $0(0)$ & $>0.05$ \\
Gastrointestinal complication & $1(2)$ & $0(0)$ & $>0.05$ \\
Endocrine/electrolyte disorder & $1(2)$ & $1(2)$ & $>0.05$ \\
\hline
\end{tabular}

Values are numbers (percentages in parentheses).

\section{NTG Use}

Three and 6 months after infusion, NTG use in the control group had decreased compared to baseline $(-3.81$ \pm 0.6 and $-4.6 \pm 2.7 \mathrm{mg}$ ), and the CD34+ stem celltreated patients also used less NTG at both time points $(-9.8 \pm 7.5$ and $-11.1 \pm 1.3 \mathrm{mg}$; table 3$)$. The decrease in NTG use in the control population, in the context of a decrease in angina, may be a reflection of better utiliza- 
Fig. 1. SPECT perfusion imaging of a celltreated patient. a The perfusion defect at baseline. $\mathbf{b}$ The improvement in perfusion after stem cell transplantation. The 1st, 3 rd and 5 th rows are 'rest' images, while the $2 \mathrm{nd}, 4$ th and 6 th rows are 'stress' images.

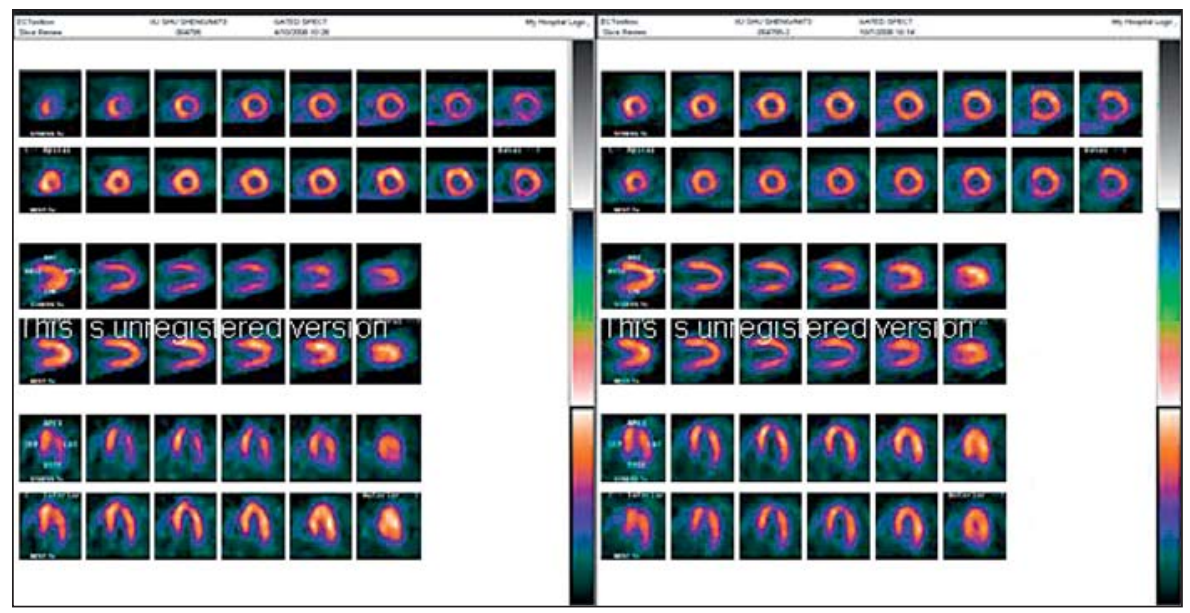

Table 3. Angina frequency, NTG use, ETT time and CCS class at baseline and 3 and 6 months after infusion

\begin{tabular}{lccl}
\hline & $\begin{array}{c}\text { Control } \\
(\mathrm{n}=56)\end{array}$ & $\begin{array}{l}\text { CD34+ cells } \\
(\mathrm{n}=56)\end{array}$ & $\mathrm{p}$ \\
& & & \\
\hline $\begin{array}{l}\text { Angina frequency, episodes per week } \\
\text { Baseline }\end{array}$ & $20.5 \pm 3.5$ & $21.2 \pm 6.1$ & $>0.05$ \\
3 months & $16.0 \pm 3.2$ & $6.6 \pm 1.3$ & $<0.01$ \\
6 months & $15.5 \pm 3.3$ & $5.6 \pm 2.1$ & $<0.01$ \\
NTG, mg per week & $16.5 \pm 0.5$ & $17.0 \pm 0.5$ & $>0.05$ \\
Baseline & $12.5 \pm 0.3$ & $7.2 \pm 0.5$ & $<0.001$ \\
3 months & $12.4 \pm 0.5$ & $6.0 \pm 1.0$ & $<0.001$ \\
6 months & & & \\
ETT, min & $4.3 \pm 1.1$ & $4.4 \pm 1.0$ & $>0.05$ \\
Baseline & $5.6 \pm 1.1$ & $7.2 \pm 1.3$ & $<0.05$ \\
3 months & $6.8 \pm 2.1$ & $8.9 \pm 1.3$ & $<0.01$ \\
6 months & & & \\
CCS class & $3.5 \pm 0.5$ & $3.3 \pm 0.5$ & $>0.05$ \\
Baseline & $3.5 \pm 0.2$ & $2.2 \pm 0.8$ & $<0.01$ \\
3 months & $2.7 \pm 1.7$ & $0.9 \pm 1.0$ & $<0.01$ \\
6 months & & & \\
\hline
\end{tabular}

Values represent means $\pm \mathrm{SE}$.

tion of NTG as a result of patient education in the course of trial participation.

\section{Exercise Tolerance}

Three months after infusion, exercise time on the standard Bruce protocol improved in both the control and treatment groups compared with baseline $(+1.3 \pm 1.1$ and $+2.8 \pm 1.3 \mathrm{~min}$, respectively). The CD34+ stem celltreated patients experienced greater improvement in ex- ercise time. Six months after infusion, exercise time on the standard Bruce protocol was further improved in control and treatment groups when compared with baseline $(+2.5 \pm 2.1$ and $+4.5 \pm 1.3 \mathrm{~min}$, respectively).

\section{CCS Class}

Three and 6 months after infusion, the mean CCS class was reduced in the control and treatment groups (3 months: $-0.051 \pm 0.2$ for controls vs. $-1.1 \pm 0.8$ for treated patients; 6 months: $-0.8 \pm 1.7$ for controls vs. $-2.4 \pm$ 1.0 for treated patients; table 3 ). The CD34+ stem celltreated patients experienced a greater reduction in CCS class at both time points. In addition, the percentage of patients experiencing a decrease in CCS class by at least 1 class was higher in the CD34+ cell-treated patients than in controls.

\section{SPECT Perfusion Imaging}

SPECT imaging at baseline and 6 months after infusion showed no significant change in defective area on stress imaging in either of the 2 groups. The perfusion defect area on the resting image was reduced in 47 of 56 patients in the treatment group, whereas 53 of 56 patients in the placebo-treated group had no significant change compared with baseline ( $\mathrm{p}<0.01$; fig. 1$)$.

\section{Discussion}

This randomized, placebo-controlled clinical trial of intracoronary infusion with autologous bone marrow CD34+ stem cells in patients with intractable angina has shown the safety of this approach. Thus far, this proce- 
dure has been primarily used for patients with acute myocardial infarction $[9,10]$. Evaluation of bioactivity provides evidence of benefit to the cell-treated patients in all of the outcome measures. These outcomes describe a successful first-in-human study.

All parameters appeared to have improved in both the placebo and treatment groups at the 3- and 6-month follow-up, namely angina frequency, NTG use, ETT and CCS class. Taking into account the small sample size and the fact that patients were recruited from a single center, we must consider the positive placebo effect. The control group received intracoronary infusion of placebo solution, and that procedure alone might exert an antiangina effect. What is the mechanism of the disease, and what is the proposed mechanism of intracoronary autologous bone marrow $\mathrm{CD} 34+$ stem cell therapy? Epicardial coronary disease is the underlying disease process in the target patient population; also, progressive angina and heart failure are known to occur in patients despite no apparent change in the epicardial coronary anatomy. Evidence suggests that attrition of the myocardial angiogenesis in both large vessels and the microvasculature occurs progressively in ischemic myocardium [11-17]. Data from preclinical models indicate that $\mathrm{CD} 34+$ cells restore the microcirculation and improve myocardial tissue perfusion by promoting repair of endothelium and enhancing angiogenesis in both large vessels and the microvasculature $[6,8,18]$. With regard to the mechanism of cell therapy, the question is whether the cells participate in new vessel formation or induce neovascularization within the tissue and circulating blood via paracrine effects. Published data have provided evidence for both mechanisms [17]. Most interesting among these data is the evidence that endothelial progenitor cells (EPCs) have a phenotype that drives their potency for neovascularization [19-22].

Our decision to choose CD34+ cells for this therapy was based on extensive preclinical data indicating that surface expression of $\mathrm{CD} 34+$ identifies a population of cells with an enhanced potency for neovascularization of ischemic tissue $[18,23]$. Other methods of enriching the population of EPCs have been established, most notably the use of cell culture, with efficacy shown in preclinical studies and more recently in clinical trials $[24,25]$. We chose CD34+ selection on the basis of preclinical data that indicated enhanced efficacy and safety with CD34+ versus unselected cells $[6,7]$ and because a device was commercially available that could be used to purify the CD34+ cells from patients, thereby obviating the requirement for a current Good Manufacturing Practices facility at each treatment site. Accordingly, autologous bone marrow CD34+ stem cells with potency for therapeutic neovascularization could be produced at practically any hospital and would be more convenient for transplantation by intracoronary infusion if this strategy were successful. Thus, there would be fewer barriers to applying this treatment on a very large scale. The dose was chosen according to the number of mononuclear cells present in $120-150 \mathrm{ml}$ of bone marrow.

For more and more patients with diffuse triple-vessel disease and CCS class III or IV angina, there is no significant reduction in symptoms of angina in treated versus control patients. Thus, effective stem cell therapy showing evidence of biological activity is desirable. Exercise testing has been widely used as a surrogate for symptomatic improvement in studies of antianginal therapies; however, several characteristics distinguish these prior studies from the intractable angina population. The target population for therapy of intractable angina is older and has a higher rate of multivessel disease, prior myocardial infarction and prior bypass surgeries. Accordingly, the ability to increase exercise performance in this population may be restricted by other factors, which limits the potential utility of the ETT. In addition, some prior studies in the intractable angina population have shown increases in exercise time in the placebo group of nearly $1 \mathrm{~min}$ [26]. This fact is particularly interesting when viewed in the context of a randomized, controlled trial of percutaneous transluminal coronary angioplasty (PTCA) versus best medical therapy [27]. In an unblinded study of relatively young patients with single-vessel disease, the PTCA-treated patients experienced a 90-second improvement in total exercise time compared with those randomized to the control arm [26]. If we consider the placebo effect, documented to increase exercise time by $30-60 \mathrm{~s}$ in blinded studies, the impact of PTCA to alleviate angina on total exercise time is apparently quite small.

We evaluated the perfusion defect of myocardial ischemia by SPECT imaging, which appears to be a logical candidate to provide objective evidence of neovascularization. However, our expectations in this regard were tempered by the fact that SPECT imaging has been validated primarily for the detection of epicardial and microvascular disease, and it is particularly suited for detecting gradients in perfusion that result from disease of both large vessels and the microvasculature. Thus, although SPECT imaging, as a standard clinical modality, is being applied in most clinical trials of neovascularization, the tool is being scrutinized to determine its suitability for accurately assessing outcomes. Both positron 
emission tomography-computed tomography and magnetic resonance imaging offer possible advantages for the assessment of perfusion and function, but these applications remain experimental. In addition, we hope that molecular imaging techniques may offer precise assessment of a meaningful biological end point that would enable confident assessment of our attempts at angiogenesis [27-31].

A recently published multicenter trial investigating intramyocardial transplantation of autologous CD34+ stem cells for intractable angina shows a prevalent perspective [3]. Published studies by Assmus et al. [24] and Schachinger et al. [25] have provided evidence for the therapeutic potency of cultured EPCs for the treatment of ischemic disease. The present data add to this evidence that CD34+ stem cells, isolated from the bone marrow, can be safely transplanted via intracoronary infusion and may improve perfusion by promoting angiogenesis in both large vessels and the microvasculature and reduce symptoms in patients with advanced coronary disease who have exhausted the currently available therapeutic armamentarium. Our randomized trial of therapy with autologous CD34+ cells in patients with intractable angina could prove the safety and feasibility of the convenient intracoronary infusion approach and provides evidence for bioactivity in this patient population.

\section{Clinical Perspective}

This report details a first-in-human experience with intracoronary transplantation of autologous bone marrow $\mathrm{CD} 34+$ cells for intractable angina. The study design was based on preclinical data that provided evidence that selected CD34+ cells were safer and more effective for revascularization of ischemic myocardium. The target population in this study, with a condition estimated to have an annual incidence in China of 300,000 per year, included patients with class III and class IV angina refractory to medical treatment and not amenable to revascularization. Features that distinguish this trial from previous reports include the fact that (1) it was performed in China, (2) its patients experienced angina with chronic ischemia, (3) selected CD34+ stem cells collected from the bone marrow were used, and (4) the more convenient method of intracoronary transplantation. This pilot study provided evidence for safety and feasibility and also revealed trends that favor the treatment versus control in all of the parameters assessed.

\section{Acknowledgements}

The authors gratefully acknowledge the support of Ying Han, MD, and Zhijun Yang, MD, in the inception and completion of this project. The authors thank Wei Sun, MD, for technical support during the study. We also thank Qibo Cheng, MD, for administrative support.

\section{References}

1 Wenaweser P, Windecker S: Acute coronary syndromes: management and secondary prevention. Herz 2008;33:25-37.

-2 Yang EH, Barsness GW, Gersh BJ, Chandrasekaran K, Lerman A: Current and future treatment strategies for refractory angina. Mayo Clin Proc 2004;79:1284-1292.

$\checkmark 3$ Losordo DW, Schatz RA, White CJ, Udelson JE, Veereshwarayya V, Durgin M, Poh KK, Weinstein R, Kearney M, Chaudhry M, Burg A, Eaton L, Heyd L, Thorne T, Shturman L, Hoffmeister P, Story K, Zak V, Dowling D, Traverse JH, Olson RE, Flanagan J, Sodano D, Murayama T, Kawamoto A, Kusano KF, Wollins J, Welt F, Shah P, Soukas P, Asahara T, Henry TD: Intramyocardial transplantation of autologous CD34+ stem cells for intractable angina: a phase I/IIa double-blind, randomized controlled trial. Circulation 2007; 115:3165-3172.
-4 Fukumoto Y, Miyamoto T, Okamura T, Gondo H, Iwasaki H, Horiuchi T, Yoshizawa S, Inaba S, Harada M, Niho Y: Angina pectoris occurring during granulocyte colony-stimulating factor-combined preparatory regimen for autologous peripheral blood stem cell transplantation in a patient with acute myelogenous leukaemia. Br J Haematol 1997; 97:666-668

$\checkmark 5$ Wilson RF, Henry TD: Granulocyte colonystimulating factor and granulocyte-macrophage colony-stimulating factor: doubleedged swords. J Am Coll Cardiol 2005;46: 1649-1650.

6 Iwasaki H, Kawamoto A, Ishikawa M, Oyamada A, Nakamori S, Nishimura H, Sadamoto K, Horii M, Matsumoto T, Murasawa S, Shibata T, Suehiro S, Asahara T: Dose-dependent contribution of CD34positive cell transplantation to concurrent vasculogenesis and cardiomyogenesis for functional regenerative recovery after myocardial infarction. Circulation 2006; 113:1311-1325.
7 Kawamoto A, Iwasaki $\mathrm{H}$, Kusano K, Murayama T, Oyamada A, Silver $M$, Hulbert C, Gavin M, Hanley A, Ma H, Kearney M, Zak V, Asahara T, Losordo DW: CD34-positive cells exhibit increased potency and safety for therapeutic neovascularization after myocardial infarction compared with total mononuclear cells. Circulation 2006;114: 2163-2169.

-8 Manginas A, Goussetis E, Koutelou M, Karatasakis G, Peristeri I, Theodorakos A, Leontiadis E, Plessas N, Theodosaki M, Graphakos S, Cokkinos DV: Pilot study to evaluate the safety and feasibility of intracoronary CD133(+) and CD133(-) CD34(+) cell therapy in patients with nonviable anterior myocardial infarction. Catheter Cardiovasc Interv 2007;69:773-781.

9 Brehm M, Darrelmann E, Strauer BE: Stem cell therapy in acute myocardial infarction. Internist 2008;49:1068-1078. 
10 Zhang SN, Sun AJ, Ge JB, Yao K, Huang ZY, Wang KQ, Zou YZ: Intracoronary autologous bone marrow stem cells transfer for patients with acute myocardial infarction: a meta-analysis of randomised controlled trials. Int J Cardiol 2009;136:178-185.

- 11 Ambrosio G. Weisman HF, Mannisi JA, Becker LC: Progressive impairment of regional myocardial perfusion after initial restoration of postischemic blood flow. Circulation 1989;80:1846-1861.

12 Agata J, Chao L, Chao J: Kallikrein gene delivery improves cardiac reserve and attenuates remodeling after myocardial infarction. Hypertension 2002;40:653-659.

13 Lund GK, Watzinger N, Saeed M, Reddy GP, Yang M, Araoz PA, Curatola D, Bedigian M, Higgins CB: Chronic heart failure: global left ventricular perfusion and coronary flow reserve with velocity-encoded cine MR imaging: initial results. Radiology 2003;227:209215.

14 Selvanayagam JB, Jerosch-Herold M, Porto I, Sheridan D, Cheng AS, Petersen SE, Searle N, Channon KM, Banning AP, Neubauer S: Resting myocardial blood flow is impaired in hibernating myocardium: a magnetic resonance study of quantitative perfusion assessment. Circulation 2005;112:3289-3296.

15 Ortak J, Akin I, Kische S, Nienaber CA, Ince $\mathrm{H}$ : Stem cell use for cardiac diseases as of 2008. Transfus Apher Sci 2008;38:253-260.

16 Tse HF, Lau CP: Therapeutic angiogenesis with bone marrow-derived stem cells. J Cardiovasc Pharmacol Ther 2007;12:89-97.

17 Losordo DW, Dimmeler S: Therapeutic angiogenesis and vasculogenesis for ischemic disease. II. Cell-based therapies. Circulation 2004;109:2692-2697.
18 Ariani M, De Servi S, Chianese R, Beria G, Gatti A, Poletti F, Del Rosso G, Fetiveau R, Poli A, Macchi M, Brando B: Circulating CD34-positive cell number is related to effective myocardial reperfusion in acute myocardial infarction treated with primary coronary angioplasty. J Cardiovasc Med 2008;9: 677-682.

19 Surdacki A, Marewicz E, Wieteska E, Szastak G, Rakowski T, Wieczorek-Surdacka E, Dudek D, Pryjma J, Dubiel JS: Association between endothelial progenitor cell depletion in blood and mild-to-moderate renal insufficiency in stable angina. Nephrol Dial Transplant 2008;23:2265-2273.

20 Hristov M, Zernecke A, Schober A, Weber C: Adult progenitor cells in vascular remodeling during atherosclerosis. Biol Chem 2008; 389:837-844.

21 Huang PH, Chen YH, Chen YL, Wu TC, Chen JW, Lin SJ: Vascular endothelial function and circulating endothelial progenitor cells in patients with cardiac syndrome X. Heart 2007;93:1064-1070.

22 Kawamoto A, Gwon HC, Iwaguro H, Yamaguchi JI, Uchida S, Masuda $\mathrm{H}$, Silver M, Ma H, Kearney M, Isner JM, Asahara T: Therapeutic potential of ex vivo expanded endothelial progenitor cells for myocardial ischemia. Circulation 2001;103:634-637.

23 Asahara T, Murohara T, Sullivan A, Silver M, van der Zee R, Li T, Witzenbichler B, Schatteman $\mathrm{G}$, Isner JM: Isolation of putative progenitor endothelial cells for angiogenesis. Science 1997;275:964-967.

24 Assmus B, Honold J, Schachinger V, Britten MB, Fischer-Rasokat U, Lehmann R, Teupe C, Pistorius K, Martin H, Abolmaali ND, Tonn T, Dimmeler S, Zeiher AM: Transcoronary transplantation of progenitor cells after myocardial infarction. N Engl J Med 2006; 355:1222-1232.
25 Schachinger V, Erbs S, Elsasser A, Haberbosch W, Hambrecht R, Holschermann H, Yu J, Corti R, Mathey DG, Hamm CW, Suselbeck T, Assmus B, Tonn T, Dimmeler S, Zeiher AM; REPAIR-AMI Investigators: Intracoronary bone marrow-derived progenitor cells in acute myocardial infarction. N Engl J Med 2006;355:1210-1221.

26 Parisi AF, Folland ED, Hartigan P; Veterans Affairs ACME Investigators: A comparison of angioplasty with medical therapy in the treatment of single-vessel coronary artery disease. N Engl J Med 1992;326:10-16.

$>27$ Red-Horse K, Ferrara N: Imaging tumor angiogenesis. J Clin Invest 2006;116:25852587.

28 Bialostozky D, Rodríguez-Diez G, Zazueta C: Apoptosis detection in cardiovascular diseases through nuclear cardiology SPECT images (in Spanish). Arch Cardiol Mex 2008; 78:217-228.

29 Russell RR 3rd, Zaret BL: Nuclear cardiology: present and future. Curr Probl Cardiol 2006;31:557-629.

30 Blocklet D, Toungouz M, Berkenboom G, Lambermont M, Unger P, Preumont N, Stoupel E, Egrise D, Degaute JP, Goldman M, Goldman S: Myocardial homing of nonmobilized peripheral-blood CD34+ cells after intracoronary injection. Stem Cells 2006;24: 333-336.

-31 Syed MA, Paterson DI, Ingkanisorn WP, Rhoads KL, Hill J, Cannon RO 3rd, Arai AE: Reproducibility and inter-observer variability of dobutamine stress CMR in patients with severe coronary disease: implications for clinical research. J Cardiovasc Magn Reson 2005;7:763-768. 